\title{
PENINGKATAN KUALITAS LAYANAN INDIHOME MENGUNAKAN METODE SERVICE QUALITY, QUALITY FUNCTION DEPLOYMENT DAN NET PROMOTERS SCORE DI PT TELKOM AKSES
}

\section{IMPROVING THE QUALITY OF INDIHOME SERVICES USING METHOD OF SERVICE QUALITY, QUALITY FUNCTION DEPLOYMENT AND NET PROMOTERS SCORE IN PT TELKOM AKSES}

\author{
Fahmi $^{(1)}$, Kohar Sulistyadi ${ }^{(2)}$ dan Lisa Ratnasari ${ }^{(3)}$ \\ ${ }^{(1)}$ Alumni Fakultas Teknik Program Studi Teknik Industri Universitas Sahid \\ ${ }^{(2)}$ Dosen Program Studi Doktor Ilmu Komunikasi SPs Universitas Sahid \\ ${ }^{(2)}$ Dosen Program Studi Teknik Industri Universitas Sahid \\ e-mail:ksulisyadi@gmail.com
}

\begin{abstract}
ABSTRAK
Kualitas produk dan layanan merupakan salah satu kunci sukses dalam persaingan. adanya keterkaitan antara kualitas jasa, kepuasan konsumen, minat membeli dan reputasi di mata konsumen. PT Telkom Indonesia sebagai penyedia layanan tetap (voice dan broadband) dengan merek Indihome melalui anak perusahaan PT Telkom Akses. Layanan internet broadband ini mempunyai peran penting dalam meningkatkan kualitas hidup. Indihome berusaha untuk meningkatkan Kualitas layanan, Untuk itu Indihome memanfaatkan digital network basis teknologi fiber optic, yang membentang dari ujung barat sampai timur Indonesia. Kepuasan pelanggan akan semakin dipenuhi dengan jaringan fiber optic yang mampu menyediakan layanan akses internet dengan kecepatan tinggi dengan koneksi yang lebih stabil dan handal. Penelitian ini menggunakan metode Service Quality dan Quality Function Deployment untuk mememberiakn parameter antara persepsi dan harapan pelanggan serta metode Net Promotor Score untuk memberikan informasi besarnya keinginan pelanggan dalam memakai kembali produk atau jasa yang ditawarkan dan merekomedasikan. Input yang digunakan untuk perhitungan metode Quality Function Deployment dan Net Promotor Score adalah output yang dihasilkan dari metode service quality yang akan menghasilkan atribut penting dari kinerja yang dilakukan dan masih dianggap kurang maksimal untuk menjadi prioritas perbaikan. Berdasarkan hasil penelitian tingkat kepuasan pelanggan terhadap pelayanan indihome kurang memuaskan, dimana dari 24 atribut ada 6 atribut yang kurang memuaskan bagi pelangan sementara 18 atribut lainya belum mencapai target yang diharapkan, selain itu pada penelitian ini didapatkan usulan perbaikan dari kontribusi karakteristik house of quality dan net promoters score dalam rangka meningkatkan kualitas pelayanan Indihome di PT Telkom Akses Jakarta Selatan.
\end{abstract}

Kata Kunci: Kualitas pelayanan, Service Quality, Quality Function Deployement, Net Promoters Score

\begin{abstract}
Product and service quality is one of the keys to success in competition. there is a link between service quality, customer satisfaction, buying interest and reputation in the eyes of consumers. PT Telkom Indonesia as a fixed service provider (voice and broadband) with the Indihome brand through its subsidiary PT Telkom Akses. This broadband internet service has an important role in improving the quality of life. Indihome strives to improve service quality. For this reason, Indihome utilizes a digital network based on fiber optic technology, which stretches from the western end to the eastern part of Indonesia. Customer satisfaction will be increasingly met by fiber optic networks that are able to provide high-speed internet access services with more stable and reliable connections. This study uses the Service Quality and Quality Function Deployment methods to
\end{abstract}


provide parameters between customer perceptions and expectations and the Net Promotor Score method to provide information on the amount of customer desire in reusing products or services offered and recommended. The input used for the calculation of the Quality Function Deployment and Net Promoter Score methods is the output generated from the service quality method that will produce important attributes of the performance performed and are still considered to be less than the maximum priority for improvement. Based on the results of research the level of customer satisfaction with indihome services is less satisfactory, where of the 24 attributes there are 6 attributes that are less satisfactory for customers while 18 other attributes have not reached the expected target, other than that in this study it was proposed to improve the contribution of house of quality and net characteristics promoters score in order to improve the quality of Indihome services at PT Telkom Akses South Jakarta.

Keywords: Service quality, Service Quality, Quality Function Deployment, Net Promoters Score

\section{Pendahuluan}

\subsection{Latar Belakang Masalah}

Kualitas produk dan layanan merupakan kunci sukses dalam persaingan. adanya keterkaitan antara kualitas jasa, kepuasan konsumen, minat membeli (purchase intention) dan reputasi di mata konsumen. Sebagai perusahaan telco digital PT Telkom Indonesia menyediakan layanan tetap (voice dan broadband) dengan merek Indihome melalui anak perusahaan PT Telkom Akses. Indihome berbasis teknologi fiber optic yang menyediakan layanan akses internet berkecepatan tinggi. Kualitas koneksi lebih stabil dan handal.

Pengakuan terhadap usaha dan kualitas layanan PT Telkom Indonesia tercermin dari banyak penghargaan lembaga yang kredibel. Pada The Best Contact Centre Operations, PT Telkom Indonesia meraih kategori "Gold" dan "Platinum" pada The Best Technology Innovation. Kategori "Platinum "diperoleh pada The Best Social Media dari ICCA 2016. Penghargaan bergengsi terbaru 2016 yang didapat oleh PT Telkom Indonesia adalah Pemenang ke 2 Indonesia Contact Centre Award dari ICCA (Indonesia Contact Center Association), dan Winners The Best CCI 2016.

Tantangan mewujudkan komitmen peningkatan kualitas layanan dibutuhkan usaha keras dan dan inovasi, kualitas layanan yang prima kepada pelanggan. Untuk itu PT Telkom Indonesia sangat mengharapkan masukkan konstruktif dari setiap pelanggan agar mereka mendapatkan layanan terbaik, khususnya layanan Indihome. Dalam kesempatan ini akan diterapkan metode Service Quality, Quality Function Deployment dan Net Promoters Score untuk meningkatkan kualitas layanan Indihome di PT Telkom Akses. Untuk itu perlu kajian tentang "Peningkatan kualitas layanan Indihome mengunakan metode Service Quality, Quality Function Deployment dan Net Promoters Score Di PT Telkom Akses".

\subsection{Tujuan Penelitian}

Tujuan penelitian ini difokuskan pada: (1) memperoleh tingkat harapan dan persepsi pelanggan dalam pelayanan Indihome; dan (2) memberikan usulan perbaikan kualitas pelayanan bedasarkan keinginan pelanggan dan sistem kerja saat ini.

\section{Tinjauan Pustaka}

Teknik servqual dapat mengetahui seberapa besar jarak harapan pelanggan dengan ekspektasi pelanggan terhadap pelayanan yang diterima untuk itu perlu dikaji Service quality (servqual) 


\section{Service Quality}

Service quality (servqual) merupakan dimensi pengukuran kualitas layanan yang dibuat menggunakan kuesioner kedalam 5 dimensi yaitu tangibles, reliability, responsiveness, assurence, emphaty. Sulistyadi, Kohar, dan S. L Susanty. (2005), menjelaskan pentingnya suatu rancangan perbaikan kualitas pelayanan jasa melalui metode Servqual, Importance Performance Analysis, dan Quality Function Deployment (QFD)

\section{Quality Function Deployment}

metode quality function deployment ( $Q F D)$ merupakan penjaminan kualitas produk dan jasa, penilaian konsumen terhadap produk dan jasa, perancangan angket kebutuhan konsumen, survei konsumen, penyusunan daftar periksa serta matrik House of Quality.

Siahay et. al 2002 menjelaskan penerapan $Q F D$ pada Pendidikan Tinggi atau Jasa tidak dapat hanya dijelaskan berdasarkan peningkatan kualitas pelayanan saja. Berbeda dengan Sulistyadi dan Susanty (2005) membahas peningkatan kualitas produk nyata

\section{Net Promoters Score}

Dharmawan, Angga, (2014) menguraikan metode ini merupakan metrik loyalitas pelanggan yang memprediksi kemungkinan seorang pelanggan membeli kembali atau merekomendasikan. Net promoter score sebagai metode yang flexible, mudah beradaptasi dengan sistem opensource.

\section{Serat Optik}

Serat optik adalah saluran transmisi sejenis kabel yang terbuat dari kaca, sangat halus, lebih kecil dari sehelai rambut dan dapat digunakan untuk mentransmisikan sinyal cahaya dari suatu tempat ke tempat lain. Sumber cahaya yang digunakan biasanya adalah laser(light emitting diode). Pada prinsipnya serat optik memantulkan dan membiaskan sejumlah cahaya yang merambat didalamnya.

Dalam penggunaan serat optik ini, memiliki kemampuan dalam membawa banyak data yang dapat memuat kapasitas informasi sangat besar dengan kecepatan transmisi mencapai gigabyte-per detik dan menghantarkan informasi jarak jauh tanpa pengulangan, Serat optik non penghantar, tanpa energy listrik dan percikan api.

\section{Metodologi Penelitian}

Penelitian ini dilakukan di PT Telkom Akses Jakarta Selatan yang dilaksanakan pada bulan Januari sampai Februari 2018. Dimulai dengan melakukan observasi untuk mengamati proses bisnis baik didalam kantor maupun dilapangan dan kemudian membuat kuesioner untuk mengumpulkan data dari responden dimana peneliti membuat pertanyaan yang telah diatur sedemikian rupa untuk mengetahui apakah pelayanan Indihome yang di berikan oleh PT Telkom Akses ini telah sesuai dengan harapan pelanggan atau belum. Dalam pembuatan kuesioner disini menggunakan uji kecukupan data untuk menentukan besaran sample dan mengkorelasikan antara nilai yang didapat dari setiap petanyaan dengan nilai total individu untuk menyatakan validitas dan realibilitas kuesioner ini yang diperoleh dengan menggunakan software IBM SPSS Statistics version 24 for Windows. Setelah itu melakukan wawancara dan diskusi bersama pihak manajemen untuk mencari kesepakatan dalam memperbaiki dan meningkatkan kualitas layanan. realibilitas.

\section{Hasil Dan Pembahasan}

\subsection{Perancangan Kuesioner}

Kuesioner terdiri dari 24 atribut pelayanan nilai tingkat harapan dan persepsi ini dihitung mengunakan nilai modus (angka yang sering muncul). Dalam penelitian ini yang 
dijadikan kompetitor adalah Trans Vision sebagai penyedia layanan internet dan berada diwilayah Jakarta Selatan. Sebelumnya perusahaan ini dikenal sebagai Telkom Vision sebelum diambil alih oleh Trans Corp. Atribut pelayanan hasil dari kuesioner dapat ditinjukkan pada Tabel 1.

Tabel 1. Atribut pelayanan nilai tingkat harapan dan persepsi

\begin{tabular}{|c|c|c|c|c|c|}
\hline \multirow{3}{*}{$\stackrel{\bar{\varrho}}{\bar{\Xi}}$} & \multirow[b]{3}{*}{ NO } & Atribut & \multicolumn{3}{|c|}{ Nilai Modus } \\
\hline & & \multirow[b]{2}{*}{ Pelayanan Indihome } & \multirow{2}{*}{$\begin{array}{l}\text { Tingkat } \\
\text { Harapan }\end{array}$} & \multicolumn{2}{|c|}{ Tingkat Persepsi } \\
\hline & & & & Indihome & $\begin{array}{l}\text { Trans } \\
\text { Vision }\end{array}$ \\
\hline \multirow{5}{*}{ 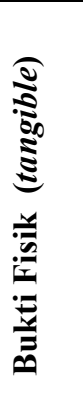 } & 1 & $\begin{array}{l}\text { Kebersihan, kerapihan dan kesopanan karyawan (teknisi, } \\
\text { customer service, sales) }\end{array}$ & 4 & 4 & 3 \\
\hline & 2 & Prosedur administrasi pelayanan yang memudahkan saudara & 4 & 4 & 3 \\
\hline & 3 & $\begin{array}{l}\text { Aplikasi my indihome dapat memudahkan informasi dan } \\
\text { manfaat bagi saudara }\end{array}$ & 4 & 4 & 3 \\
\hline & 4 & $\begin{array}{l}\text { Tersedianya fasilitas pendukung dalam menuggu antrian di } \\
\text { Plasa Telkom kami (majalah/koran, free wifi, TV, AC, coffe } \\
\text { break, kotak saran, tempat sampah dan area parkir) }\end{array}$ & 4 & 4 & 3 \\
\hline & 5 & $\begin{array}{l}\text { Kenyamanan ruang tunggu atau counter pelayanan (Plasa, } \\
\text { Kantor Telkom) }\end{array}$ & 4 & 4 & 4 \\
\hline \multirow{5}{*}{ 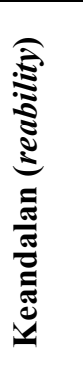 } & 6 & $\begin{array}{l}\text { Kemampuan komunikasi petugas (teknisi, customer service, } \\
\text { sales, karyawan) dalam menjawab pertanyaan cukup } \\
\text { meyakinkan }\end{array}$ & 4 & 4 & 4 \\
\hline & 7 & Pelayanan yang diberikan sesuai yang ditawarkan & 4 & 4 & 4 \\
\hline & 8 & $\begin{array}{l}\text { Kejelasan informasi yang diberikan oleh customer service } \\
\text { atau karyawan kepada pelanggan (akurat dan update) }\end{array}$ & 5 & 4 & 4 \\
\hline & 9 & $\begin{array}{l}\text { Petugas kami melakukan check langsung kerumah saudara } \\
\text { untuk melihat kondisi layanan }\end{array}$ & 4 & 4 & 4 \\
\hline & 10 & Kemampuan petugas kami terhadap produk knowledge & 4 & 4 & 4 \\
\hline \multirow{4}{*}{ 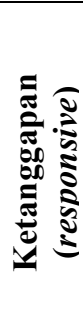 } & 11 & Selalu merespon keluhan pelanggan dengan cepat dan tepat & 5 & 4 & 3 \\
\hline & 12 & $\begin{array}{l}\text { Memberikan tanggapan positif terhadap keluhan yang } \\
\text { dihadapi pelanggan }\end{array}$ & 5 & 4 & 4 \\
\hline & 13 & $\begin{array}{l}\text { Pada saat perbaikan layanan dilokasi, apakah kordinasi } \\
\text { antara teknisi dilapangan dengan bagian administrasi kami } \\
\text { berjalan dengan baik }\end{array}$ & 4 & 4 & 3 \\
\hline & 14 & $\begin{array}{l}\text { Security memberikan arahan pelayanan sesuai dengan } \\
\text { kebutuhan pelanggan (Plasa, Kantor Telkom) }\end{array}$ & 4 & 4 & 3 \\
\hline \multirow{5}{*}{ 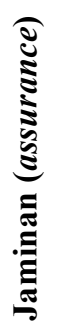 } & 15 & $\begin{array}{l}\text { Melakukan perbaikan terhadap keluhan dengan cepat dan } \\
\text { tepat }\end{array}$ & 5 & 4 & 3 \\
\hline & 16 & $\begin{array}{l}\text { Solusi yang diberikan memuaskan saudara (kredibilitas } C S \text {, } \\
\text { teknisi, karyawan) }\end{array}$ & 5 & 4 & 4 \\
\hline & 17 & Pembayaran sesuai dengan pelayanan yang didapat & 4 & 4 & 4 \\
\hline & 18 & $\begin{array}{l}\text { Sebelum melalukan perbaikan, apakah petugas kami } \\
\text { memberikan informasi secara jujur dan jelas }\end{array}$ & 4 & 4 & 4 \\
\hline & 19 & Keyakinan pelanggan pada solusi yang diberikan petugas & 4 & 4 & 4 \\
\hline \multirow{5}{*}{ 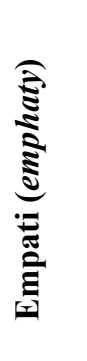 } & 20 & $\begin{array}{l}\text { Pendekatan customer service pada pelanggan dengan ramah } \\
\text { dan sabar }\end{array}$ & 4 & 4 & 5 \\
\hline & 21 & Perusahaan selalu menginformasikan promo menarik & 4 & 4 & 4 \\
\hline & 22 & $\begin{array}{l}\text { Memberikan hadiah atau reward jika pelanggan } \\
\text { memberikan kritikan, masukan bagi perusahaan }\end{array}$ & 4 & 3 & 4 \\
\hline & 23 & $\begin{array}{l}\text { Petugas kami mendengarkan serta menanggapi keluhan } \\
\text { pelanggan dengan penuh rasa empati }\end{array}$ & 4 & 4 & 4 \\
\hline & 24 & $\begin{array}{l}\text { Petugas kami memberikan arahan kepada pelanggan dalam } \\
\text { mengatasi masalah dengan ramah, sabar dan sampai tuntas }\end{array}$ & 4 & 4 & 3 \\
\hline
\end{tabular}


Untuk mengukur nilai dimensi service quality atas jasa pelayanan yang diterima pelanggan / masyarakat Untuk itu perlu dinilai tingkat harapan dan tingkat persepsi pelanggan dalam dimensi service quality sebagai Karakteristik Teknik yang dapat ditunjukkan pada Tabel 2.

Tabel 2. Penentuan karakteristik teknik melalui diskusi dan konsultasi pihak PT Telkom Akses

\begin{tabular}{|c|c|c|c|c|c|c|c|}
\hline \multirow{3}{*}{$\begin{array}{c}\text { Dimensi } \\
\text { Bukti fisik (tangible) }\end{array}$} & \multirow{3}{*}{$\begin{array}{c}\begin{array}{c}\text { Tingkat } \\
\text { Harapan }\end{array} \\
4,00\end{array}$} & \multicolumn{2}{|c|}{ Tingkat Persepsi } & \multicolumn{4}{|c|}{ Score Servqual } \\
\hline & & $\begin{array}{c}\text { Indi } \\
\text { home }\end{array}$ & $\begin{array}{c}\text { Trans } \\
\text { Vision }\end{array}$ & \multicolumn{2}{|c|}{ Indihome } & \multicolumn{2}{|c|}{ Trans Vision } \\
\hline & & 4,00 & 3,20 & 0,00 & Memuaskan & $-0,80$ & $\begin{array}{l}\text { Kurang } \\
\text { Memuaskan }\end{array}$ \\
\hline Keandalan (reability) & 4,20 & 4,00 & 4,00 & $-0,20$ & Memuaskan & $-0,20$ & $\begin{array}{l}\text { Kurang } \\
\text { Memuaskan }\end{array}$ \\
\hline $\begin{array}{l}\text { Ketanggapan } \\
\text { (responsive) }\end{array}$ & 4,50 & 4,00 & 4,00 & $-0,50$ & Memuaskan & $-0,50$ & Memuaskan \\
\hline Jaminan (assurance) & 4,40 & 4,00 & 3,80 & $-0,40$ & Memuaskan & $-0,60$ & $\begin{array}{l}\text { Kurang } \\
\text { Memuaskan }\end{array}$ \\
\hline Empati (emphaty) & 4,00 & 3,80 & 4,00 & $-0,20$ & Memuaskan & 0,00 & $\begin{array}{l}\text { Kurang } \\
\text { Memuaskan }\end{array}$ \\
\hline
\end{tabular}

Prioritas ditentukan berdasarkan normalisasi kontribusi dapat diurutkan berdasarkan Tabel 3.

Tabel 3. Penentuan Prioritas Karakteristik Teknik

\begin{tabular}{clcc}
\hline NO & \multicolumn{1}{c}{ Karakteristik Teknik } & $\begin{array}{c}\text { Normalisasi } \\
\text { Kontribusi }\end{array}$ & Prioritas \\
\hline 1 & Disiplin operasional & 0,179 & 1 \\
2 & Menerapkan budaya solid, speed, smart & 0,150 & 2 \\
3 & Melakukan Pendekatan Staff kepada pelanggan & 0,132 & 3 \\
4 & Quality control & 0,125 & 4 \\
5 & Menerapkan budaya 4S & 0,112 & 5 \\
6 & Menjalankan Prosedur administrasi dengan benar & 0,082 & 6 \\
7 & Melakukan penerapan SOP & 0,068 & 7 \\
8 & Melakukan pengembangan kepada seluruh karyawan & 0,068 & 8 \\
9 & Menerapkan budaya 6R & 0,039 & 9 \\
10 & Memaksimalkan teknologi sistem informasi & 0,029 & 10 \\
11 & Melakukan Penataan layout dan keamanan & 0,014 & 11 \\
12 & Melakukan evaluasi petugas secara berkala & 0,002 & 12 \\
\hline
\end{tabular}

Penilaian kebutuhan pelanggan, karakteristik teknis, planning matriks, korelasi teknik, nilai kontribusi dan prioritas yang berbentuk dalam Matriks House of quality yang dapat dapat dilihat pada Tabel 4. 
Tabel 4. Matriks House Of Quality

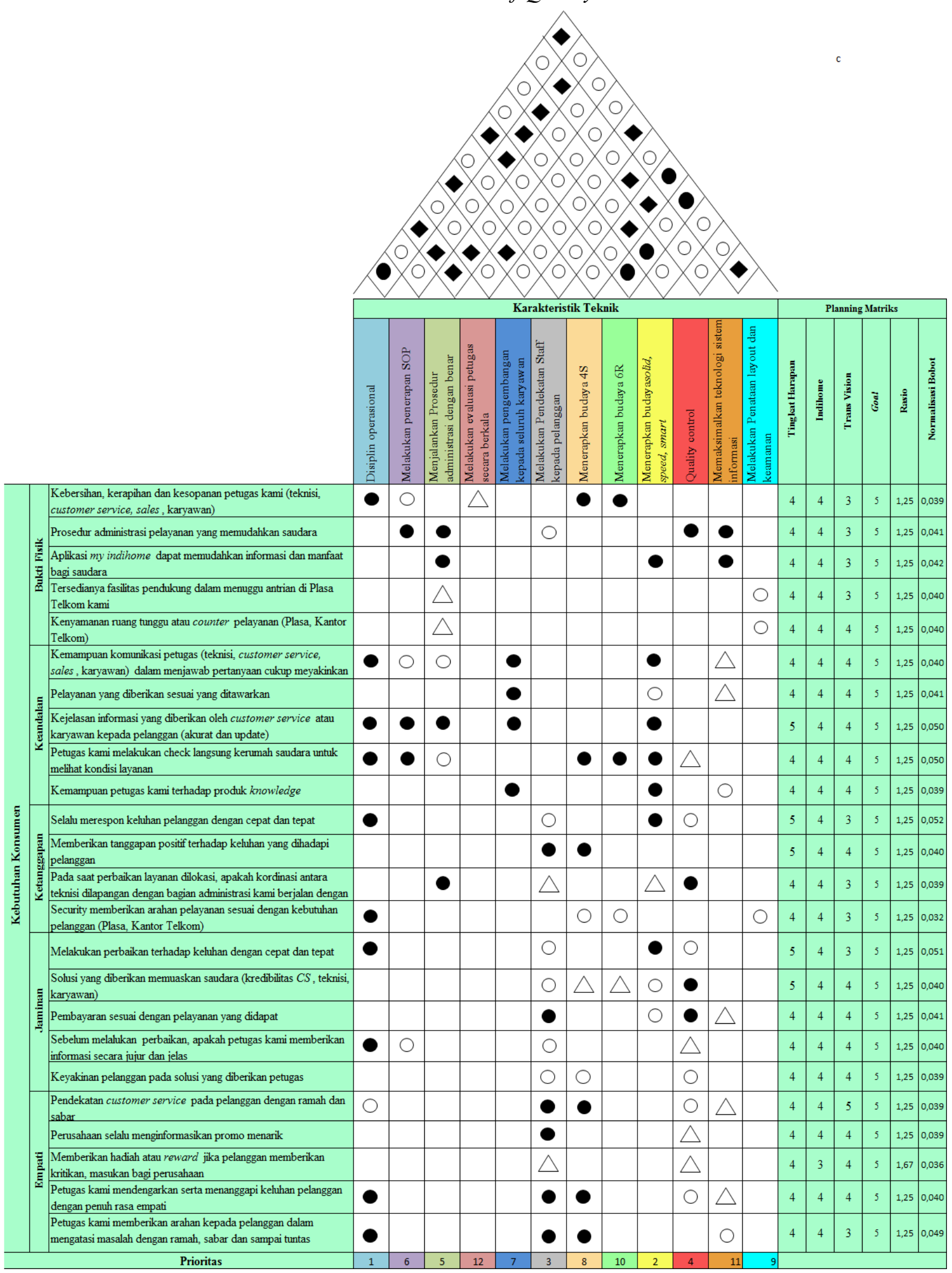




\section{Net Promoters Score}

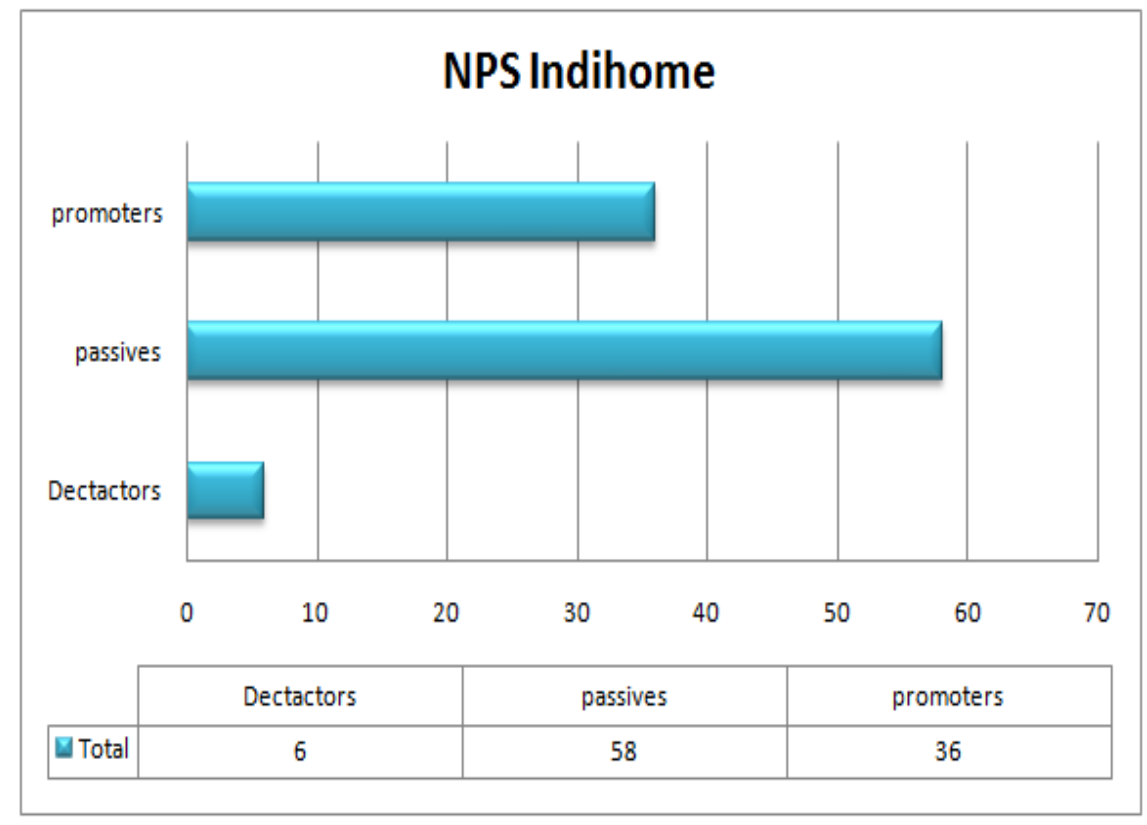

Perhitungan Net Promoters Score :

$$
\begin{aligned}
\text { NPS } & =\text { Promoters }- \text { Dectactor } \\
& =36-6 \\
& =30
\end{aligned}
$$

Berdasarkan perhitungan diatas didapatkan net promoters score sebesar 30 pelanggan. Jika net promoter score anda adalah 36 apa arti sebenarnya, net promoter score sebesar score 36 memberikan arti bahwa nilai Score promoter adalah kuat, jika dibandingkan dengan rata-rata net promoter score beberapa organisasi dalam industri. Jadi dapat diinterpretasikan bahwa responden yang merekomendasikan lebih banyak dan mau merekomendasikan Indihome kepada teman kenalannya atau pelanggan lainnya.

\section{Kesimpulan Dan Saran}

\subsection{Kesimpulan}

Berdasarkan pengolahan data maka dapat ditarik kesimpulan dan saran sebagai berikut :

1. Tingkat harapan pelanggan dalam pelayanan Indihome,

a) Kejelasan informasi yang diberikan oleh customer service atau karyawan kepada pelanggan (akurat dan update), dengan nilai (5);

b) Selalu merespon keluhan pelanggan dengan cepat dan tepat, dengan nilai (5);

c) Memberikan tanggapan positif terhadap keluhan yang dihadapi pelanggan, dengan nilai (5);

d) Melakukan perbaikan terhadap keluhan dengan cepat dan tepat, dengan nilai (5);

e) Solusi yang diberikan memuaskan saudara (kredibilitas customer service, teknisi, karyawan), dengan nilai (5);

f) Memberikan hadiah atau reward jika pelanggan memberikan kritikan, masukan bagi perusahaan, dengan nilai (4).

Tingkat persepsi pelanggan dalam pelayanan Indihome, 
1) Informasi dari customer service atau karyawan kepada pelanggan dengan nilai (4);

2) Respon keluhan pelanggan dengan cepat dan tepat, dengan nilai (4);

3) Tanggapan positif terhadap keluhan yang dihadapi pelanggan, dengan nilai (4);

4) Melakukan perbaikan terhadap keluhan dengan cepat dan tepat, dengan nilai (4);

5) Solusi yang memuaskan (customer service, teknisi, karyawan), dengan nilai (4);

6) Memberikan hadiah atau reward melalui kritikan, bagi perusahaan, dengan nilai (3).

Usulan perbaikan bedasarkan urutan prioritas,

1) Disiplin operasional;

2) Menerapkan budaya solid, speed, smart;

3) Melakukan pendekatan staff kepada pelanggan;

4) Quality control;

5) Menerapkan 4S;

6) Menjalankan prosedur administrasi dengan benar;

7) Melakukan penerapan SOP;

8) Melakukan pengembangan kepada seluruh karyawan;

9) Menerapkan budaya 6R;

10) Memaksimalkan teknologi sistem informasi;

11) Melakukan Penataan layout dan keamanan;

12) Melakukan evaluasi petugas secara berkala.

2. Usulan perbaikan bedasarkan net promoters score. Terhadap pelanggan passive perusahaan dapat menaruh fokus untuk mengubah pelanggan yang passive menjadi promoters dengan terus memberikan pelayanan yang baik dan memberikan pengalaman menariknya dari Indihome. Sementara terhadap pelanggan detractors yang harus dilakukan adalah menginvestigasi mengapa mereka memiliki pengalaman yang tidak menyenangkan. Dengan mengetahui jawaban dari pelanggan, PT Telkom Akses dapat mengatasi dan memperbaiki aspek tertentu dan membantu mengubah detractors menjadi passive atau promoter dengan memberikan penawaran yang tidak dapat ditolak.

\subsection{Saran}

Pihak manajemen PT Telkom Akses harus dapat mengerti bagaimana supaya langkah langkah yang telah diusulkan dapat dijalankan dan berhasil, dengan cara berikut :

1. Ada evaluasi berkala terhadap pencapaian target yang diinginkan.

2. Dilakukan studi / penelitian seperti ini untuk jangka waktu tertentu misalnya setiap dua tahun atau secara periodik.

3. Melakukan perbaikan pelayanan pelanggan Indihome berdasarkan urutan prioritas karakteristik teknik dan hasil dari net promoters score

4. Menunjukan kualitas yang baik agar reputasi yang dimiliki produk dapat terjaga dan meningkatkan, termasuk dengan cara menjaga kecepatan akses internet. Hal tersebut dimaksudkan untuk memberikan kepuasan terhadap pelanggan, karena jika pelanggan tersebut puas maka pelanggan tersebut akan loyal.

Studi ini perlu dilakukan lagi karena kedepannya akan banyak terjadi perubahan dari waktu ke waktu, baik dari segment teknologi, pasar, konsumen, pesaing dan peraturan.

\section{Daftar Pustaka}

Amaku, Amaku, Raphael E.Watti, John Joshua, 2014. Optic Fiber as a Reliable Medium for Metropolitan Area Networking (MAN) Connectivity: Nigeria 
Balasubramanian, M, 2016. Total Quality Management [TQM] in the Healthcare Industry - Challenges, Barriers and Implementation Developing a Framework for TQM Implementation in a Healthcare Setup: India

Dharmawan, Angga, 2014. Rancangan Perbaikan Kualitas Pelayanan Jasa Dengan Metode Servqual, Importance Performance Analysis, Dan Quality Function Deployment Pada Plasa Telkom Cabang Dinoyo Surabaya : Surabaya

Elrod, Cassandra Elrod, Sarah Stanley, Elizabeth Cudney, and Caroline Fisher, 2015. Empirical Study Utilizing QFD to Develop an International Marketing Strategy: USA

Faiz, Gaboul Ahmed, 2016. The Role Of Market Orientation On The Relationship Between Total Quality Management Dimensions And Organizational Performance: A Study On Banks In Libya: Libya

Gencer, Yasin Galip and Ulas Akkucuk, 2016. Measuring Quality In Automobile Aftersales: Autoservqual Scale: Turkey

Petrova, Virginia, 2015. Ghost shopping as a method of improving a company's marketing and customer relationship and satisfaction: Finland

Pratama, I Putu Gede Yudha, G.Sukadarmika, P.K.Sudiarta, 2017. Perancangan Jaringan Fiber To The Home (FTTH) Menggunakan Teknologi Gigabyte Passive Optical Network (GPON) pada Mall Park23 Tuban: Bali

Rajagukguk, dan Retno Setyorini, 2016. Peningkatan Kualitas Pelayanan Dengan Metode Service Quality Dan Metode Quality Function Deployment (Qfd) (Studi Pelayanan

Siahay, Steven, Sulistyadi, Kohar, Nendissa, Benny, 2002, Penerapan Model Quality Function of Deployment (QFD) Pada Institusi Pendidikan Tinggi, Seminar Nasional Teknik Industri dan Manajemen Produski, ITS.

Sulistyadi, Kohar, dan S. L Susanty. 2005, Perencanaan Peningkatan Kualitas Sepatu Olah raga Berdasarkan Quality Function Deployment, Jurnal Teknik Industri UID Vol 5, No.11, p 83-90

Wicaksono, Adhitya Wahyu, 2013, Penerapan Metode QFD (QualityFunction Deployment) Pada Rencana Pengembangan Sekolah di SMKN 2 Yogyakarta: Yogyakarta.

Xu, Yanping, Ping Lu, Liang Chen and Xiaoyi Bao, 2017. Recent Developments in MicroStructured Fiber Optic Sensors: Canada 